\title{
TAKING THE ALTERNATIVE MAINSTREAM
}

\section{Euan Adie}

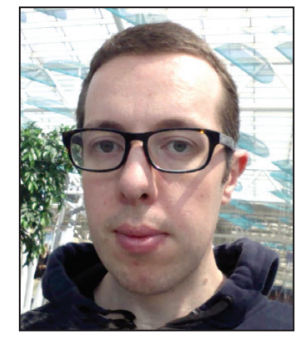

Euan Adie is the founder of Altmetric, a data science start up based in London that helps researchers explore the broader online impact of their work. Before that he was a senior product manager at Nature Publishing Group, where he looked after products ranging from an online reference manager to NPG's mobile apps. Originally a computer scientist, Adie became interested in publishing and post-publication review after working as a bioinformatics researcher at the University of Edinburgh.

http://orcid.org/0000-0001-9227-4188

Altmetric LLP, The Macmillan Building 4 Crinan St., London, N1 9XW, UK euan@altmetric.com

\section{Abstract}

The reasons for the use of "alternative metrics" to measure the influence that the publication of a specific scientific work has on society are discussed. It is argued that altmetrics are complementary to the traditional system of counting citations, and can be used in much broader contexts.

\section{Keywords}

Altmetrics, Alternative metrics, Impact, Citations count, Citations, Impact assessment, Scientific articles.

\section{Título: Adopción de la principal corriente alternativa}

\section{Resumen}

Se comentan las razones que justifican el uso de las llamadas "métricas alternativas" para medir la influencia que la publicación de los trabajos científicos concretos tiene en la sociedad. Se argumenta que las altmétricas son complementarias al sistema tradicional de conteo de citaciones, y pueden usarse en contextos mucho más amplios.

\section{Keywords}

Altmétricas, Métricas alternativas, Impacto, Conteo de citas, Citaciones, Evaluación del impacto, Artículos científicos.

Adie, Euan (2014). "Taking the alternative mainstream". El profesional de la información, julio-agosto, v. 23, n. 4, pp. 349-351.

http://dx.doi.org/10.3145/epi.2014.jul.01

\section{The birth of altmetrics}

Alternative metrics, sometimes shortened to just altmetrics, is an umbrella term covering new ways of approaching, measuring and providing evidence for impact.

Though information scientists, funders and publishers have all been interested in this subject for a long time it's only in the past three or four years that altmetrics have attracted widespread interest at conferences, in research journals and from the commercial sector. Three things came together to birth the field as we know it today.

The first is recognition from governments and funders that the return on investment from research -something that has come sharply into focus as budgets are frozen or reduced- is both important to measure and not limited to economic benefit.

The second is the wholesale shift of research material from print to online. It is rare for a publisher launching a new journal to create a print edition. Academics discover, consume, share and discuss research online. Early landmark studies like Mesur (Bollen et al., 2008) have demonstrated the richness of the resulting digital patterns.

Finally, the publication of The altmetrics manifesto (Priem, 2010), driven by passionate academics like Jason Priem who then went on to found ImpactStory with Heather Piwovar- gave the field a focal point and a name. 


\section{Altmetric}

\section{We make article level metrics easy.}

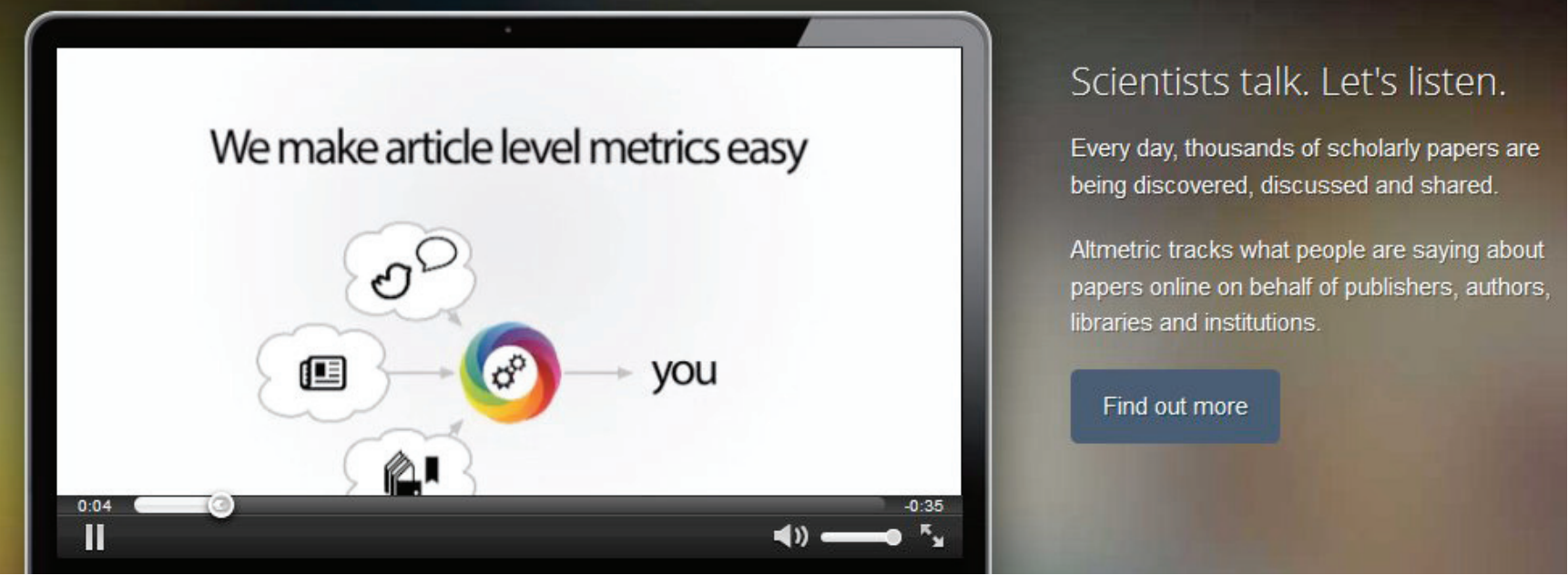

http://altmetric.com

\section{Alternative to what?}

The "alternative" part of alternative metrics is to what you might call the traditional view of research metrics: using citations to measure impact, sometimes on a journal level using the impact factor as a proxy.

In my view the guiding principle of altmetrics is that we should help people get credit where credit is due by taking a broader view of impact.

There are many kinds of impact-economic, social, politicalon many audiences -the public, practicioners, other scholars. At different times it is useful for different things. Sometimes quantitative measures may be most appropriate, at other times a qualitative assessment is required. In some cases you can look at just research articles, and sometimes you need to look at a broader range of outputs.

\section{We should simply recognize that citation based metrics aren't suitable for every purpose}

None of this necessarily involves replacing citation based metrics, we should simply recognize that they aren't suitable for every purpose. Alternative metrics might better described as complementary metrics -but 'complimetrics' doesn't have the same ring to it.

Why should we care about these other types of impact? Because researchers do. If a scientist writes a useful piece of software why should she have to write a paper about it that can be cited by others in order to get any recognized credit for it? If a clinical researcher writes a paper to reach a particular audience -say policy makers- that doesn't typically write papers themselves shouldn't you still be able to highlight and then provide evidence for that influence too?

\section{Uptake of altmetrics}

Publishers and institutions have been quick to take to altmetrics of various forms, and many journal platforms support the provision of altmetrics in some form as standard; altmetric.com alone serves some $4 \mathrm{M}$ requests for data a day, and some publishers like PLOS successfully run in-house altmetrics collection programmes.

Interestingly one of the primary drivers of usage of altmetrics is authors looking at their own work, rather than other people's. This makes sense: if you published a paper tomorrow, would you interested in who else might read or discuss it? Would you want to have some indication of whether or not it was getting more or less attention that you might expect?

Partly this is, for lack of a better word, an ego thing. It's natural as an author to want to know who has seen your work, who is reading it properly, commenting on it, citing it. In this context, however, egotism isn't a negative character trait. Rather it's something that you need to have developed to be a successful researcher -grants don't go to people who can't demonstrate that they've had any influence in their field.

Practically speaking this means that the majority of academic publishers using altmetrics do so as an author service, linking to altmetrics data reports from each article.

Using the data for discovery is less popular amongst publishers, perhaps because of the more complicated integrations required for their platforms. That said several successful pilots have been run by Elsevier (showing articles that have been taIked about recently on journal homepages) and others.

Altmetrics are also used in other areas: by institutions as an awareness tool, for research admin or for reputation management; by funders, looking for evidence to help show that grant funded research outputs are giving value for money and by mainstream media to pick up interesting stories before they've been picked up in other media outlets. 


\section{Challenges}

Before altmetrics can truly be considered mainstream there are several challenges to overcome.

One is simply a common understanding of exactly what altmetrics are and how they should be used: the price of rapid progress in the field has been some confusion over exactly what is being claimed; about what's hope and what's hype and what circumstances the data is to be used in.

\section{Altmetrics are used in areas other than} research metrics

Another is to get stakeholder communities involved in the further development of altmetrics tools and best practice. Up until now altmetrics has been driven by the people working in that field (and coming, generally, from academic research or publishing backgrounds). If altmetrics are to be truly useful to, for example, a small biomedical funder then we need small biomedical funders to be speaking up and talking about what the data they need is.

Finally, data availability and reliability is critical. Citations have the benefit of being for the most part stable, captured in the scholarly record and clearly recorded, at least since the advent of CrossRef, Scopus and Web of science. The nature of altmetrics data is that it is much more transient and difficult to capture, at least in a way that allows for clear auditing and tracking data back to the source.

\section{Conclusion}

Though the concept of altmetrics has existed for many years, since 2010 the field has been maturing rapidly and is in use by many academic publishers and institutions.

However, challenges remain, around both use cases and the data, and initiatives like the annual altmetrics conferences in the US and Europe, NISO's altmetrics standards process and DORA (the San Francisco Declaration on Research Assessment) will be important to guiding the field towards the mainstream.

The price of rapid progress in altmetrics has been some confusion over exactly what is being claimed

\section{Bibliography}

Bollen, Johan; Van-de-Sompel, Herbert; Rodríguez, Marko A. (2008). "Towards usage-based impact metrics: first results from the mesur project". Procs of the $8^{\text {th }}$ ACM/IEEE-CS Joint conf on digital libraries (pp. 231-240). http://dx.doi.org/10.1145/1378889.1378928

Priem, Jason T. (2010). The altmetrics manifesto. Retrieved from The altmetrics manifesto (October, 26): http://altmetrics.org/manifesto

\title{
Anuario ThinkEPI 2014
}

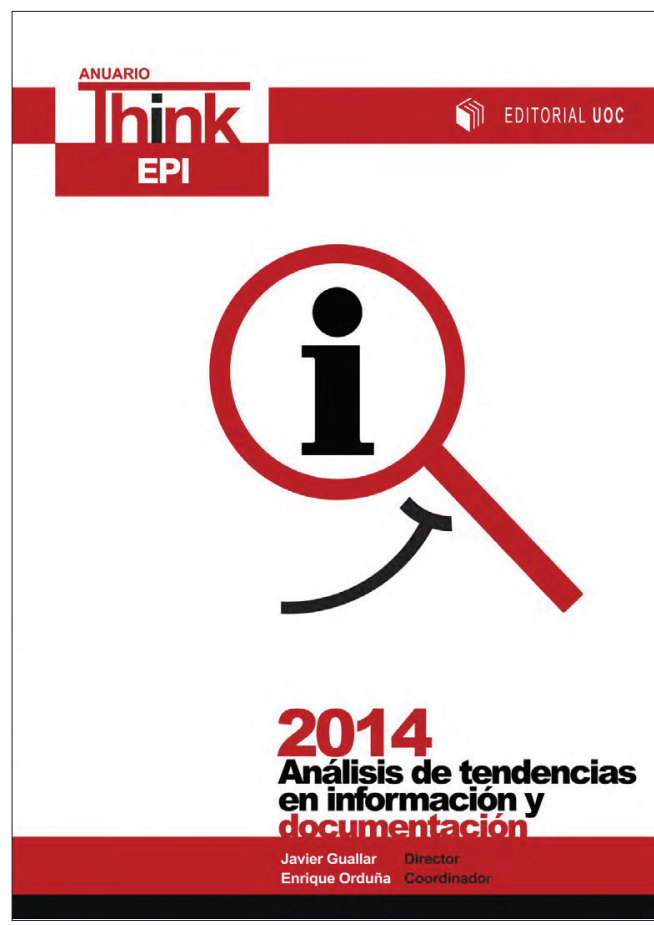

\section{4 páginas de análisis de tendencias en información, documentación y comunicación Disponible sólo en formato digital}

\author{
Formulario de compra: \\ http://www. \\ elprofesionaldelainformacion.com/ \\ suscripciones.php
}

Información y pedidos: Isabel Olea

epi.iolea@gmail.com +34608491521 